\title{
Potencial fisiológico de sementes de diferentes lotes de abóboras Caserta e Moranga
}

\author{
Physiological quality of seeds of different lots of pumpkin \\ Caserta and Pumpkin
}

Rita Hermínia Vaz de Souza ${ }^{1 *}$, Francisco Amaral Villela1,2, Tiago Zanatta Aumonde

Departamento de Fitotecnia, Faculdade de Agronomia Eliseu Maciel, Universidade federal de Pelotas (UFPel), Caixa Postal 354 CEP 96001-970, Pelotas, RS, Brasi

${ }^{2}$ Bolsista Produtividade em Pesquisa Nivel I do CNPq.

* autor correspondente

$\nabla$ ritavaz.bage@hotmail.com
RESUMO: Objetivou-se avaliar a eficiência de testes vigor na distinção de lotes de sementes de abóboras Caserta e Moranga, Cucurbita maxima e Cucurbita pepo, respectivamente. Utilizaram-se quatro lotes de cada espécie, cuja qualidade inicial foi verificada através da determinação de umidade e teste de germinação. O vigor das sementes foi avaliado através da velocidade de germinação e de emergência de plântulas, comprimento e massa de matéria seca de plântulas, envelhecimento acelerado e condutividade elétrica. $\mathrm{O}$ teste de condutividade elétrica diferencia os lotes de sementes de abóbora Caserta, destacando os lotes de maior e de menor vigor. Os testes de crescimento de plântulas (massa seca e comprimento) apresentam baixa eficiência a diferenciação de lotes de sementes de abóbora em níveis de vigor.

PALAVRAS-CHAVE: Cucurbita maxima, Cucurbita pepo, testes de vigor, condutividade elétrica.
ABSTRACT: This study aimed to evaluate the efficiency of the tests for separation of seed lots of pumpkins Caserta and moranga, Cucurbita maxima and Cucurbita pepo, respectively. Were utilized four lots of each species, whose initial quality was verified through the moisture determination and the germination test. The seed vigor was evaluated through the speed of germination and of seedling emergence, length and mass of dry matter of seedlings, accelerated aging and electrical conductivity. The test of electrical conductivity differentiates in manner consistent of pumpkin seeds Caserta, standing out the lots of larger and lesser vigor. The tests of seedling growth (dry matter and length) lodge limited efficiency in the differentiation lots of pumpkin seeds into levels vigor.

KEYWORDS: Cucurbita maxima, Cucurbita pepo, vigor tests, electrical conductivity. 


\section{Introdução}

A qualidade fisiológica da semente reflete-se na expressão do potencial genético desta e no melhor desenvolvimento de plântulas nos estádios iniciais, podendo afetar diversas variáveis de crescimento e resultar em alteração de produtividade. O desempenho de sementes de hortaliças é, rotineiramente, avaliado pelo teste de germinação.

O referido teste é conduzido sob condições favoráveis ao processo germinativo e ao crescimento inicial e assim permite que diferentes lotes que apresentem qualidades distintas expressem seu máximo potencial de formação de plântulas normais, muitas vezes apresentando resultados diferentes dos obtidos em campo (PESKE et al., 2012).

A utilização de testes de vigor no controle de qualidade de sementes produzidas complementa as informações obtidas no teste de germinação e permite a obtenção de resultados com maior reprodutibilidade sob condições adversas de campo (PESKE et al., 2012). O vigor reflete-se na capacidade de desempenho das plântulas expostas às diferentes condições de ambiente, e possibilita detectar atributos mais sutis da qualidade fisiológica, não revelados pelo teste de germinação (PESKE et al., 2012).

Testes de vigor baseados no desempenho de plântulas, de condutividade elétrica, de envelhecimento acelerado e de frio são recomendados na avaliação do vigor de sementes (MARCOS FILHO, 2005). Existem regras para análise de sementes, incluindo testes de vigor, para algumas espécies vegetais, estabelecidas por órgãos/instituições de pesquisa, como por exemplo, ISTA (International Seed Testing Association), AOSA (Association of Official Seed Analysts) e MAPA (Ministério da Agricultura, Pecuária e Abastecimento).

Para sementes de abóbora e melancia pode ser utilizado o teste de primeira contagem da germinação (CASAROLI et al., 2009; BHERING et al., 2005). Já para rúcula, o teste de condutividade elétrica é recomendado (LEAL et al., 2012), enquanto para melão, o teste de envelhecimento acelerado é aconselhável (TORRES; MARCOS FILHO, 2005) e para tomate, o de emergência de plântulas (BARROS et al., 2002). Todavia, a avaliação de testes de vigor em sementes de abóbora é escassa, podendo os resultados ser variáveis entre lotes de diferentes espécies, ou mesmo, dentro de lotes de uma mesma espécie.

As abóboras, espécies pertencentes a família Cucurbitaceae, apresentam ampla aceitação popular, e ocupam posição de destaque entre as hortaliças mais consumidas no Brasil, ocupando desta forma extrema importância no cenário do agronegócio (ARAÚJO et al., 2012). No Brasil, a região Nordeste destaca-se pela produção desta cultura, contribuindo com $24,1 \%$ de toda a produção nacional, sendo que, a Bahia, Maranhão e Pernambuco são os Estados que apresentam a maior produção desta espécie (RESENDE et al., 2013).

Neste contexto, este trabalho objetivou avaliar a eficiência de testes vigor na distinção de lotes de sementes de abóbora.

\section{Material e Métodos}

O trabalho foi conduzido no Laboratório Didático de Análise de Sementes do Departamento de Fitotecnia da Faculdade de Agronomia Eliseu Maciel, na Universidade Federal de Pelotas, em Pelotas - RS.
Foram utilizados oito lotes de sementes, sendo quatro de abóbora Moranga (Cucurbita maxima) e quatro de abóbora Caserta (Cucurbita pepo). As sementes, não submetidas a tratamento químico, foram adquiridas nas empresas Hortec Sementes Ltda. e ISLA Sementes. Durante o período experimental, os lotes permaneceram armazenados em câmara incubadora sob temperatura de 18 a $20{ }^{\circ} \mathrm{C}$ e umidade relativa de $40-45 \%$, em embalagens de polipropileno trançado.

Na primeira etapa os lotes foram submetidos a testes para avaliação da qualidade física e fisiológica das sementes, de forma a promover caracterização e possível classificação prévia. Para tanto, foram realizados os seguintes testes:

Grau de umidade (GU): conduzido pelo método de estufa à temperatura de $105 \pm 3{ }^{\circ} \mathrm{C}$, durante 24 horas (BRASIL, 2009), utilizando duas repetições de $5,0 \mathrm{~g}$ de sementes. Os resultados foram expressos em porcentagem (\%) média de umidade (em base úmida) para cada lote.

Teste de germinação (G): foram utilizadas quatro subamostras de 50 sementes por lote, distribuídas em rolos de papel toalha "Germitest", previamente umedecido com água destilada, na quantidade de 2,5 vezes a massa do substrato seco para os lotes da espécie Moranga, e de 2,0 vezes o peso do substrato seco para a espécie Caserta (em função das diferenças de tamanho e peso das sementes entre as espécies, e conforme ensaios preliminares), e colocadas para germinar a temperatura de $25^{\circ} \mathrm{C}$. As avaliações foram realizadas aos quatro e oito dias após a semeadura, conforme descrito nas RAS (BRASIL, 2009). Os resultados foram expressos em porcentagem (\%) média de plântulas normais.

Em função da contaminação por fungos e bactérias, observada preliminarmente no teste de germinação, e comprovada a partir de teste de sanidade, para as avaliações posteriores foi realizada descontaminação prévia, com solução de hipoclorito de sódio. A solução utilizada foi preparada com $1 \%$ de ingrediente ativo. As sementes permaneceram 10 minutos imersas na solução desinfestante e após foram lavadas em água corrente, durante três minutos (PESKE et al., 2012).

$\mathrm{Na}$ segunda etapa, os lotes de sementes foram submetidos a testes para avaliação do vigor. Para tanto, foram realizados os seguintes testes:

Emergência de plântulas em campo (EC): realizada em solo do tipo planossolo, por meio de oito repetições de 50 sementes por lote, distribuídas em linhas a $3,0 \mathrm{~cm}$ de profundidade, com espaçamento de $10 \mathrm{~cm}$ entre sementes na mesma linha e de $30 \mathrm{~cm}$ entre linhas. A avaliação foi realizada no $14^{\circ}$ dia após a semeadura e os resultados expressos em porcentagem de emergência de plântulas por lote.

Índice de velocidade emergência (IVE): calculada a partir da contagem diária do número de plântulas emergidas no ensaio de emergência de plântulas em campo e utilizando-se a equação: $I V G=G 1 / N 1+G 2 / N 2+\ldots$ Gn $/ \mathrm{Nn}$. Sendo $: \mathrm{G}_{\mathrm{n}}$ - número de sementes germinadas no n-ésimo dia; $\mathrm{N}$ - número de dias após a semeadura. 


\section{Comprimento de plântula (parte aérea e raiz primária):} realizado com oito repetições de 10 sementes (com três subamostras por lote), perfazendo 240 sementes por lote. As sementes foram dispostas sobre uma linha horizontal traçada no terço superior do substrato, a uma distância de $9,3 \mathrm{~mm}$ da borda superior da folha, com a extremidade da radícula orientada para baixo. A quantidade de água no substrato foi, para a Caserta, de 2,0 (duas) vezes e para a Moranga de 2,5 (duas e meia) vezes a massa seca do papel. Os rolos foram acondicionados no interior de sacos plásticos para manter a umidade do substrato uniforme durante o teste e colocados em germinador a temperatura constante de $25^{\circ} \mathrm{C}$, sem luz.

A avaliação do teste, aos sete dias, foi realizada respeitando a ordem de semeadura dos lotes. Com auxílio de uma régua milimetrada, foram mensuradas as medidas das plântulas normais, sendo medida a parte aérea, a partir da curva do hipocótilo (onde foi feito o corte) até o início da raiz primária, e a raiz primária do seu início até a extremidade. Considerou-se comprimento mínimo de $2 \mathrm{~cm}$ (tanto na parte aérea, quanto na raiz) e, no caso de serem fasciculadas (sem raiz principal), as que apresentassem pelo menos quatro raízes, de comprimento $\geq 4 \mathrm{~cm}$.

O comprimento de plântulas foi determinado, segundo as indicações da AOSA (ASSOCIATION OF OFFICIAL SEED ANALYSTS, 2002) e da ISTA (INTERNATIONAL SEED TESTING ASSOCIATION, 2004), onde: a) PA (AOSA) - comprimento da parte aérea de plântulas, em centímetros, dividido pelo número de plântulas normais; b) PA (ISTA) - comprimento da parte aérea de plântulas (em cm), dividido pelo número de sementes colocadas para germinar; c) RP (AOSA) - comprimento da raiz primária de plântulas, em centímetros, dividido pelo número de plântulas normais; d) RP (ISTA) comprimento da raiz primária de plântulas, em centímetros, dividido pelo número de sementes colocadas para germinar; e) CT (AOSA) - comprimento total de plântulas $(\mathrm{em} \mathrm{cm})$ dividido pelo número de plântulas normais; f) CT (ISTA) comprimento total de plântulas $(\mathrm{em} \mathrm{cm})$ dividido pelo número de sementes colocadas para germinar.

Massa da matéria seca de plântulas: utilizaram-se as plântulas inteiras (parte aérea + raiz primária) oriundas do teste de comprimento de plântulas, as quais foram acondicionadas em sacos de papel pardo e mantidas em estufa a temperatura de $80{ }^{\circ} \mathrm{C}$, durante 24 horas (NAKAGAWA, 1999). Após a secagem, o material teve sua massa aferida em balança de precisão e os dados de foram divididos pelo número de plântulas normais (AOSA) ou pelo número de sementes colocadas para germinar (ISTA), sendo estes expressos em gramas $(\mathrm{g})$.

Envelhecimento acelerado (EA): em função das diferenças de tamanho e peso das sementes, entre os distintos lotes, foram contadas cerca de 600 sementes por lote, e acrescidas de $10 \mathrm{~g}$ de sementes por amostra, para a avaliação do grau de umidade, após o período de envelhecimento. O material foi distribuído sobre a superfície de telas metálicas, suspensas no interior de caixas gerbox, sendo no primeiro teste empregadas quatro caixas e, no segundo teste, sete caixas. Sob as telas foram colocados $40 \mathrm{~mL}$ de água destilada no interior do gerbox. Na parte interna das tampas foram coladas folhas de papel mata-borrão para evitar a condensação de água sobre as sementes. As caixas, tampadas, permaneceram no interior de câmara de germinação tipo B.O.D, a temperatura de $41^{\circ} \mathrm{C}$ (CASAROLI et al., 2006), por 48 horas. A seguir, as sementes foram submetidas ao teste de germinação conforme procedimento descrito anteriormente, porém com uma única contagem no sexto dia (CASAROLI et al., 2006).

Condutividade elétrica (CE): foram utilizadas quatro subamostras de 25 e de 50 sementes por lote cuja massa foi aferida em balança de precisão, sendo dispostas para embeber em recipientes plásticos contendo $75 \mathrm{~mL}$ de água destilada, a temperatura de $20^{\circ} \mathrm{C}$. As leituras foram efetuadas após 18 e 24 horas de embebição, sendo os resultados expressos em $\mu \mathrm{S} \mathrm{g}{ }^{1}$. Assim, as medidas de condutividade elétrica da solução de embebição das sementes foram as seguintes: a) CE (50) 18 horas - condutividade elétrica com 50 sementes/ 18 horas; b) CE (50) 24 horas - condutividade elétrica com 50 sementes/ 24 horas; c) CE (25) 18 horas - condutividade elétrica com 25 sementes/ 18 horas; d) CE (25) 24 horas condutividade elétrica com 25 sementes/ 24 horas.

Os dados foram submetidos separadamente a análise da variância para cada teste e espécie de abóbora, em delineamento inteiramente casualizado, com cinco repetições, sendo a comparação entre as médias de lotes efetuada pelo teste de Tukey, em nível de probabilidade de 5\%.

\section{Resultados e Discussão}

As sementes de Moranga apresentaram massa de matéria seca em média duas vezes maior que as sementes de Caserta (Tabela 1). A umidade das sementes antes do teste de envelhecimento acelerado foi semelhante entre os lotes de abóbora e a diferença entre elas não ultrapassou meio ponto percentual (Tabela 1). Quanto à umidade após o período de envelhecimento artificial das sementes no primeiro teste, houve variação máxima de 9,2 pontos percentuais (pp) no teor de umidade entre os lotes de Moranga, e de 10,1 pp nos lotes de Caserta. Todavia, no segundo teste verificou-se a variação de 3,6 pp para as sementes de Moranga e 1,4 pp para sementes de Caserta, demonstrando maior precisão e uniformidade do grau de umidade nas sementes do segundo teste de envelhecimento acelerado.

$\mathrm{O}$ teste de envelhecimento acelerado foi conduzido duas vezes, em função da desuniformidade dos resultados ocorrida no primeiro ensaio (Tabela 1). Esta ocorrência pode ser verificada pelos dados de germinação após o período de estresse e principalmente pela diferença entre as repetições quanto a umidade, fato demonstrado pelo maior coeficiente de variação, no primeiro teste para ambas as espécies.

É possível inferir que a falta de uniformidade verificada no primeiro teste pode ser atribuída à distribuição inadequada das sementes sobre as telas de suporte para as sementes no interior das caixas gerbox, principalmente nos lotes de sementes maiores. 
Tabela 1. Dados médios referentes à massa da matéria seca (MMS), ao grau de umidade inicial (GU), germinação inicial (G), germinação e umidade antes e após o teste de envelhecimento acelerado $\left(41^{\circ} \mathrm{C} / 48 \mathrm{~h}\right)$ de oito lotes de sementes de abóbora, espécies Moranga (Cucurbita maxima) e Caserta (Cucurbita pepo).

\begin{tabular}{|c|c|c|c|c|c|c|c|c|}
\hline \multirow{2}{*}{ Espécie } & \multirow{2}{*}{ Lote } & \multirow{2}{*}{ MMS (\%) } & \multirow{2}{*}{ GU (\%) } & \multirow{2}{*}{ G $(\%)$} & \multicolumn{2}{|c|}{ Envelhecimento acelerado (\%) } & \multicolumn{2}{|c|}{ Umidade após EA (\%) } \\
\hline & & & & & $1^{\circ}$ teste & $2^{\circ}$ teste & $1^{\circ}$ teste & $2^{\circ}$ teste \\
\hline \multirow{4}{*}{ Moranga } & 1 & 221,4 & 6,2 & 98a* & 92a* & 90a* & 26,6 & 19,2 \\
\hline & 2 & 228,1 & 6,1 & 99a & 93a & $91 \mathrm{a}$ & 27,7 & 19,8 \\
\hline & 3 & 202,6 & 6,3 & $86 b$ & $57 \mathrm{~b}$ & $64 c$ & 19,9 & 16,5 \\
\hline & 4 & 189,2 & 6,2 & 93a & $80 \mathrm{a}$ & $77 \mathbf{b}$ & 29,1 & 20,1 \\
\hline CV $(\%)$ & & & & 2,46 & 8,62 & 4,14 & & \\
\hline \multirow{4}{*}{ Caserta } & 1 & 125,7 & 7 & $92 b$ & $80 \mathrm{a}$ & $75 a$ & 35 & 20,8 \\
\hline & 2 & 101,3 & 7,1 & $86 c$ & $55 \mathrm{~b}$ & $60 \mathrm{~b}$ & 33,9 & 20 \\
\hline & 3 & 90,4 & 6,6 & $96 a$ & $85 a$ & 64ab & 24,9 & 21,4 \\
\hline & 4 & 89,4 & 6,9 & $91 b$ & $78 a$ & $71 \mathrm{ab}$ & 30,4 & 20,8 \\
\hline CV (\%) & & & & 1,58 & 9,02 & 8,15 & & \\
\hline
\end{tabular}

*Médias seguidas pela mesma letra, na coluna, não diferem entre si pelo teste de Tukey a $5 \%$ de probabilidade.

Tal afirmação baseia-se no fato de que no primeiro teste foram utilizadas quatro caixas por lote de sementes, metodologia que resultou na condensação de água sobre sementes de algumas amostras e que possivelmente ocasionou variações mais acentuadas na umidade das sementes após o período de envelhecimento.

Por outro lado, no segundo teste, para os lotes cujas sementes apresentaram maior tamanho, o período de estresse foi conduzido em sete caixas tipo gerbox, enquanto as sementes de tamanhos médio e pequeno distribuídas em seis e cinco caixas, respectivamente. Desta forma, não houve sobreposição de sementes, fato que pode refletir em maior uniformidade no grau de umidade. Neste sentido, a umidade das sementes, antes e após a exposição às condições do período de envelhecimento são indicadores essenciais da condução adequada do teste. Segundo Tillmann e Menezes (2012), após o período de exposição das sementes ao estresse imposto pelo teste de envelhecimento acelerado, são consideradas toleráveis variações de 3 a 4 pp no grau de umidade entre as amostras.

A modificação na metodologia de execução do teste de envelhecimento acelerado refletiu-se no resultado do segundo teste, particularmente na espécie Moranga, cujas sementes possuem maior tamanho, proporcionado melhor distinção entre seus lotes (Tabela 1). No primeiro teste, embora os lotes tenham sido ordenados numericamente, conforme os demais testes de vigor, houve igualdade estatística entre os lotes 1 e 2 e o lote 4 , que pode retratar maior desuniformidade entre as repetições do teste $(\mathrm{CV}=8,62 \%)$. O segundo teste, com menor coeficiente de variação $(4,14 \%)$, possibilitou a estratificação dos lotes em três níveis de vigor: maior (lotes 1 e 2), menor (lote 3 ) e intermediário (lote 4).

Para espécie Caserta, embora tenha ocorrido maior uniformidade na absorção de umidade pelas sementes durante o período de estresse, o segundo teste resultou em valores mais baixos de germinação comparativamente ao primeiro teste, e também com os resultados da Moranga (Tabela 1). As sementes de Moranga possuem maior tamanho e massa que as da espécie
Caserta. Segundo Tillmann e Menezes (2012), quanto menor o tamanho das sementes, maior sua sensibilidade às condições adversas do período de envelhecimento acelerado.

Os mesmos autores alertam para o fato de que são frequentes as recomendações de determinadas temperaturas e períodos de exposição das sementes ao envelhecimento, em função de que os mesmos foram capazes de estratificar os lotes em diferentes níveis de vigor. Entretanto, essa separação pode não representar a real condição fisiológica das sementes, as quais podem estar em nível semelhante de vigor, especialmente ao se tratar de lotes com vigor médio. De certa forma, isso ocorreu no segundo teste para a espécie Caserta, pois embora tenha havido superioridade do lote 1 sobre o lote 2 , o que é compatível com os demais testes.

A escolha da temperatura de $41^{\circ} \mathrm{C}$ para a condução do teste segue uma tendência, uma vez que é a indicação de grande parte dos pesquisadores que buscam a padronização das condições de realização do teste (CASAROLI et al., 2006; CASAROLI et al., 2009; BOLIGON et al., 2010). Aliado a isso, os dados obtidos mostram-se importantes na descrição da metodologia para a condução deste teste de vigor em sementes de abóbora, minimizar o efeito do tamanho das sementes, de forma que se tenha sempre uma camada simples de sementes sobre a tela da caixa gerbox.

O teste de emergência a campo apresenta extrema importância para determinação da utilização de sementes, assim como para fins de comercialização destas (ALMEIDA et al., 2013). No teste de emergência de plântulas em campo para sementes de Moranga, os lotes foram ranqueados da mesma forma que no teste de germinação, onde o lote 3 apresentou desempenho inferior comparativamente aos demais (Tabela 2). Esta ocorrência pode ser explicada parcialmente devido a emergência em campo ter sido conduzida na época recomendada para a espécie, pois em tal condição, a associação entre os resultados do teste de germinação e de emergência de plântulas em campo é comum.

A utilização do teste de emergência, aliado a outros testes de vigor como primeira contagem da germinação e envelhecimento 
Tabela 2. Emergência em campo (EC) e índice de velocidade de emergência (IVE), comprimento de plântula (PA= parte aérea; $\mathrm{RP}=$ raiz primária; $\mathrm{CT}=$ total) e massa de matéria seca de plântulas (MMS), obtidas de sementes de abóbora Moranga (Cucurbita maxima) e de abóbora Caserta (Cucurbita pepo), determinados pelas metodologias preconizadas pela AOSA e pela ISTA.

\begin{tabular}{|c|c|c|c|c|c|c|c|c|c|c|}
\hline \multirow{3}{*}{ Lote } & \multirow{3}{*}{ EC (\%) } & \multirow{3}{*}{ IVE } & \multicolumn{8}{|c|}{ Abóbora Moranga } \\
\hline & & & \multicolumn{2}{|c|}{ PA (cm) } & \multicolumn{2}{|c|}{$\mathbf{R P}(\mathrm{cm})$} & \multicolumn{2}{|c|}{ CT (cm) } & \multicolumn{2}{|c|}{ MMS (g) } \\
\hline & & & AOSA & ISTA & AOSA & ISTA & AOSA & ISTA & AOSA & ISTA \\
\hline 1 & $96 a^{*}$ & $17,1 \mathrm{a}$ & $7,2 \mathrm{a}$ & $6,9 a$ & $13,5 a$ & $12,8 \mathbf{a}$ & $20,7 \mathbf{a}$ & $19,7 \mathbf{a}$ & $0,038 a$ & $0,037 a$ \\
\hline 2 & 93a & $17,0 a$ & 6, a & $6,8 \mathrm{a}$ & $12,7 \mathbf{a}$ & $12,4 a$ & $19,6 a$ & $19,2 \mathbf{a}$ & $0,033 a$ & $0,032 a$ \\
\hline 3 & $80 \mathrm{~b}$ & $16,6 a$ & $9,3 \mathbf{a}$ & $7,6 \mathbf{a}$ & $14,4 \mathrm{a}$ & $11,8 \mathbf{a}$ & $23,7 a$ & $19,4 a$ & $0,046 a$ & $0,037 \mathbf{a}$ \\
\hline 4 & $93 a$ & $15,5 a$ & $7,6 \mathbf{a}$ & 6,6 & $12,7 \mathbf{a}$ & $11,0 a$ & $20,2 \mathrm{a}$ & $17,5 \mathbf{a}$ & $0,036 a$ & $0,031 \mathrm{a}$ \\
\hline \multirow[t]{2}{*}{ CV (\%) } & 4,23 & 3,73 & 12,88 & 14,17 & 9,92 & 10,44 & 9,76 & 10,69 & 14,72 & 14,77 \\
\hline & \multirow{3}{*}{ EC (\%) } & \multirow{3}{*}{ IVE } & \multicolumn{8}{|c|}{ Abóbora Caserta } \\
\hline \multirow{2}{*}{ Lote } & & & \multicolumn{2}{|c|}{ PA (cm) } & \multicolumn{2}{|c|}{$\mathbf{R P}(\mathbf{c m})$} & \multicolumn{2}{|c|}{ CT (cm) } & \multicolumn{2}{|c|}{ MMS (g) } \\
\hline & & & AOSA & ISTA & AOSA & ISTA & AOSA & ISTA & AOSA & ISTA \\
\hline 1 & $74 \mathrm{~b}$ & $15,7 \mathbf{a}$ & 8,9ab & $7,6 \mathbf{a b}$ & $11,6 a$ & $9,8 b$ & 20,5ab & $\mathbf{1 7 , 3 b}$ & $0,030 b$ & $0,026 b$ \\
\hline 2 & 80 a & $15,4 a$ & $10,5 a$ & 8,0 ab & $13,8 \mathrm{a}$ & $10,6 a b$ & $24,3 \mathrm{a}$ & $18,6 a b$ & $0,029 b$ & $0,022 b$ \\
\hline 3 & 82 a & $15,2 \mathrm{a}$ & 9,9ab & $9,3 \mathbf{a}$ & $13,3 a$ & $12,4 a$ & $23,2 \mathrm{ab}$ & $21,7 \mathrm{a}$ & $0,026 b$ & $0,024 b$ \\
\hline 4 & 82 a & $14,8 \mathrm{a}$ & $7,7 b$ & $7,0 \mathrm{~b}$ & $12,4 \mathrm{a}$ & $11,1 \mathrm{ab}$ & $20,2 b$ & $18,7 \mathrm{ab}$ & $0,038 a$ & $0,033 a$ \\
\hline CV (\%) & 1,15 & 2,66 & $\mathbf{9 , 8 1}$ & 10,3 & 6,72 & 6,64 & 7,22 & 6,64 & 7 & 6,43 \\
\hline
\end{tabular}

*Médias seguidas pela mesma letra, na coluna, não diferem entre si pelo teste de Tukey a $5 \%$ de probabilidade.

acelerado permite a classificação de lotes de semente em função da qualidade fisiológica destes (ALMEIDA et al., 2013). Por outro lado, na presente pesquisa, o índice de velocidade de emergência não se constituiu como teste eficiente para a distinção de lotes de sementes de Moranga (Tabela 2).

Os dados sobre o crescimento de plântulas para os lotes de Moranga são apresentados na Tabela 2. Observa-se que não houve diferença significativa tanto para comprimento como para massa seca entre os lotes, tanto ao empregar a metodologia preconizada pela AOSA, quanto à proposta pela ISTA. Nas medidas da parte aérea (AOSA; ISTA), da raiz primária e comprimento total (AOSA) não houve diferença estatística, verificou-se entretanto a diferença numérica favorável ao lote 3 , que é o lote que apresentou qualidade inferior, de acordo com as análises dos demais testes realizados.

Segundo Carvalho e Nakagawa (2012), sementes maiores possuem maior quantidade de reservas, podendo gerar plântulas maiores. Embora as pesquisas não sejam conclusivas a respeito da relação entre o desenvolvimento das sementes e seu desempenho, trabalhos demonstram a existência de relação direta entre o tamanho e características de potencial fisiológico de sementes (PÁDUA et al., 2010; VAZQUEZ et al., 2012; SANTOS et al., 2010).

No entanto, os resultados contradizem essa hipótese, pois o lote 3 possui massa inferior à dos lotes 1 e 2, superando apenas a massa do lote 4 (Tabela 1). Em sementes de abóbora, Casaroli et al. (2009), não consideraram os testes que expressam o crescimento de plântulas eficientes na detecção de diferenças no potencial fisiológico entre os lotes.

Para a espécie Caserta, a emergência de plântulas em campo apresentou resposta distinta da germinação tendo o lote 1 atingido desempenho inferior aos demais lotes, que alcançaram emergência próxima a $80 \%$. Embora todos os lotes tenham alcançado elevada germinação, com valores que proporcionaram a sua distinção, nas análises de vigor, os resultados apresentaram maior similaridade no desempenho dos lotes, fato que se confirmou na emergência em campo. Assim como para a espécie Moranga, na espécie Caserta o índice de velocidade de emergência não diferenciou os lotes em níveis de vigor (Tabela 2). Buscando identificar testes de vigor que permitissem diferenciar a qualidade fisiológica de lotes de sementes de abóbora, Almeida et al. (2013) também observaram variação significativa entre a germinação dos lotes.

Ainda, para a espécie Caserta, os dados apresentados na Tabela 2 indicam que o lote 3 apresentou superior performance comparando-se aos demais nas avaliações de comprimento de plântula, ao utilizar a metodologia proposta pela ISTA, que leva em conta a porcentagem de germinação das sementes. Nakagawa (1999) considera ser esta a metodologia mais apropriada, visto que pode haver lotes com baixa germinação, mas cujas plântulas apresentem alta taxa de crescimento, e vice-versa. Neste caso, pode-se então extrapolar tais dados para todo o lote, pois estão sendo consideradas também a porcentagem de sementes não germinadas e as de plântulas anormais, importantes indicativos da qualidade fisiológica das sementes.

A massa de matéria seca das plântulas foi distinta entre as espécies Caserta e Moranga (Tabela 2). Deve ficar claro que além da quantidade de assimilados armazenados na semente, a maior massa seca de plântulas, possui estreita relação com a habilidade de hidrólise e alocação de assimilados. Além disso, este fator mantém relação à constituição genética do indivíduo, ocorrendo influência do ambiente sobre tais processos fisiológicos. Assim, nota-se que os resultados para cada espécie de abóbora foram discordantes, o que deve ser considerado ao existir a pretensão de padronização de testes para avaliação de vigor de sementes. 
Tabela 3. Condutividade elétrica - $\mathrm{CE}\left(\mu \mathrm{S} \mathrm{cm}^{-1} \mathrm{~g}^{-1}\right)$ de sementes de abóbora Moranga (Cucurbita maxima) e abóbora Caserta (Cucurbita pepo), utilizando-se 25 e 50 sementes e 75 mL de água, após 18 e 24 horas de embebição, Pelotas, UFPel, 2009.

\begin{tabular}{|c|c|c|c|c|}
\hline \multicolumn{5}{|c|}{ Abóbora Moranga } \\
\hline Lote & CE $(25 \mathrm{sem} / 18 \mathrm{~h})$ & CE $(25 \mathrm{sem} / 24 \mathrm{~h})$ & CE $(50 \mathrm{sem} / 18 \mathrm{~h})$ & CE $(50 \mathrm{sem} / 24 \mathrm{~h})$ \\
\hline 1 & $54,6 c^{*}$ & $56,7 \mathrm{c}$ & $52,6 \mathrm{c}$ & $54,7 b$ \\
\hline 2 & $39,3 b$ & $40,1 b$ & $\mathbf{3 7 , 3 b}$ & $38,8 \mathbf{a}$ \\
\hline 3 & $30,7 \mathbf{a}$ & $32,3 a$ & $28,8 \mathrm{a}$ & $32,8 \mathbf{a}$ \\
\hline 4 & $36,8 a b$ & $38,0 \mathrm{ab}$ & $35,5 b$ & $38,3 a$ \\
\hline CV $(\%)$ & 7,9 & 7,11 & 6,33 & 6,88 \\
\hline \multicolumn{5}{|c|}{ Abóbora Caserta } \\
\hline Lote & CE (25 sem/ 18h) & CE (25 sem/ 24h) & CE (50 sem/ 18h) & CE (50 sem/ 24h) \\
\hline 1 & $101,7 \mathrm{c}$ & $104,7 \mathrm{c}$ & 97,0d & $102,0 d$ \\
\hline 2 & 50,9b & $52,9 b$ & $44,9 \mathrm{~b}$ & $47,1 \mathrm{~b}$ \\
\hline 3 & $29,1 \mathrm{a}$ & $30,8 \mathrm{a}$ & $25,6 a$ & $27,6 \mathrm{a}$ \\
\hline 4 & $58,3 b$ & $59,9 b$ & $55,2 \mathrm{c}$ & $58,5 \mathrm{c}$ \\
\hline CV $(\%)$ & 6,5 & 5,62 & 2,14 & 2,88 \\
\hline
\end{tabular}

*Médias seguidas pela mesma letra, na coluna, não diferem entre si pelo teste de Tukey a $5 \%$ de probabilidade.

Os resultados do teste de condutividade elétrica em sementes de Moranga estão apresentados na Tabela 3. Para esta espécie, o referido teste não se mostrou eficiente na diferenciação dos lotes de acordo com o vigor em nenhuma das metodologias testadas. O lote 1 classificado como de alta qualidade pelos testes de avaliação inicial foi aquele que alcançou os maiores valores de condutividade elétrica. Esta ocorrência pode ter relação com o fato de que sementes em processo de deterioração ou de menor vigor possuem menor capacidade de reorganização do sistema de membranas celulares, apresentando extravasamento exacerbado de eletrólitos, um indício da qualidade inferior das sementes.

Todavia para a espécie Caserta, os resultados de todos os ensaios relativos à condutividade elétrica permitiram distinguir de maneira consistente os lotes de sementes, destacando-se os lotes 3 e o lote 1 , de maior e menor vigor, respectivamente (Tabela 3). Neste contexto, é interessante ressaltar que Dutra e Vieira (2006), ao avaliarem a condutividade elétrica de sementes do híbrido de abóbora Bárbara (Cucurbita moschata Duch ex Lam.), consideraram adequada a utilização de 50 sementes em $75 \mathrm{~mL}$ de água pelo período de 8 horas e temperatura de $25{ }^{\circ} \mathrm{C}$. No entanto, os mesmos autores, em ensaio com sementes de abobrinha (Cucurbita pepo L.), indicaram a temperatura de $30^{\circ} \mathrm{C}$ como a mais adequada para a condução do teste de condutividade elétrica. Dessa forma, os resultados de condutividade elétrica podem ser afetados de acordo com o genótipo em estudo.

Os ensaios visando avaliar o nível de reorganização das membranas celulares foram conduzidos com 50 sementes comparativamente àqueles conduzidos com 25 sementes, principalmente com relação a abóbora Caserta, apresentaram redução do coeficiente de variação e assim maior precisão nos resultados obtidos. Buscando estabelecer o tamanho adequado da amostra para avaliação da condutividade elétrica em sementes de tomate, Rodo et al. (1998) concluíram que existe a necessidade de recomendações específicas de tamanho da amostra para cada cultivar avaliada. Este fato corrobora com os resultados obtidos neste trabalho.

A partir da análise geral dos resultados é possível verificar que diferentes testes de avaliação do vigor possuem diferenciada eficiência na distinção de lotes de sementes de abóbora e mantêm relação com características específicas da espécie. Neste sentido, torna-se recomendável o emprego, em conjunto, de testes baseados em princípios distintos para a avaliação do vigor de sementes de abóbora.

\section{Conclusões}

O teste de condutividade elétrica diferencia os lotes de sementes de abóbora Caserta, destacando os lotes de maior e de menor vigor.

Os testes de crescimento de plântulas (massa seca e comprimento) apresentam baixa eficiência na diferenciação de lotes de sementes de abóbora em níveis de vigor.

\section{Referências}

ALMEIDA, A. S. et al. Qualidade fisiológica de sementes de abóbora. Enciclopédia Biosfera, v. 9, n. 17, p. 2250-2258, 2013.

ARAÚJO, H. S. et al. Doses de potássio em cobertura na cultura da abóbora. Pesquisa Agropecuária Tropical, v. 42, n. 4, p. 469-475, 2012.

ASSOCIATION OF OFFICIAL SEED ANALYSTS - AOSA. Seed vigor testing handbook. Lincoln, 2002. 105 p. (Contribution, 32).

BARROS, D. I. et al. Comparação entre testes de vigor para avaliação da qualidade fisiológica de sementes de tomate. Revista Brasileira de Sementes, v. 24, p. 12-16, 2002. http://dx.doi.org/10.1590/ S0101-31222002000100003.

BHERING, M. C.; DIAS, D. C. F. S.; BARROS, D. I. Adequação da metodologia do teste de tetrazólio para avaliação da qualidade fisiológica de sementes de melancia. Revista Brasileira de 
Sementes, v. 27, p. 176-182, 2005. http://dx.doi.org/10.1590/ S0101-31222005000100022.

BOLIGON, A. A.; LÚCIO, A. D.; GARCIA, D. C. Emergência de plântulas de abóbora a partir da avaliação da qualidade das sementes. Ciência Rural, v. 40, n. 11, p. 2274-2281, 2010.

BRASIL. Ministério da Agricultura e Reforma Agrária. Regras para análise de sementes. Brasília: SNAD/CLAV, 2009. 398 p.

CARVALHO, N. M.; NAKAGAWA, J. Sementes: ciência, tecnologia e produção. 5. ed. Jaboticabal: FUNEP, 2012, 590 p.

CASAROLI, D. et al. Teste de envelhecimento acelerado em sementes de abóbora. Revista da Faculdade de Zootecnia, Veterinária e Agronomia, v. 13, p. 197-207, 2006.

CASAROLI, D. et al. Testes para determinação do potencial fisiológico de sementes de Abóbora. Acta Scientiarum. Agronomy, v. 31, p. 337-343, 2009. http://dx.doi.org/10.4025/actasciagron.v31i2.7040.

DUTRA, A. S.; VIEIRA, R. D. Teste de condutividade elétrica para a avaliação do vigor de sementes de abobrinha. Revista Brasileira de Sementes, v. 18, p. 117-122, 2006. http://dx.doi.org/10.1590/ S0101-31222006000200015.

INTERNATIONAL SEED TESTING ASSOCIATION - ISTA. Seed science and technology. In: INTERNATIONAL SEED TESTING ASSOCIATION - ISTA. International rules for testing seeds. Bassersdorf, 2004. v. 32. 403 p.

LEAL, C. C. P. et al. Validação de testes de vigor para sementes de rúcula (Eruca sativa L.). Revista Brasileira de Biociências, v. 10, p. 421-424, 2012.

MARCOS FILHO, J. Fisiologia de sementes de plantas cultivadas Piracicaba: Fealq, 2005. 495 p.

NAKAGAWA, J. Testes de vigor baseados no desempenho das plântulas. In: KRZYZANOWSKI, F. C.; VIEIRA, R. D.; FRANÇA NETO, J. B. (Eds.). Vigor de sementes: conceitos e testes. Londrina: ABRATES, 1999. p. 1-24.
PÁDUA, G. P. et al. Influência do tamanho da semente na qualidade fisiológica e na produtividade da cultura da soja. Revista Brasileira de Sementes, v. 32, n. 3, p. 9-16, 2010.

PESKE, S. T.; VILLELA, F. A.; MENEGUELLO, G. E. Sementes: fundamentos científicos e tecnológicos. Pelotas: Editora e Gráfica Universitária, 2012. 573 p.

RESENDE, G. M.; BORGES, R. M.; GONÇALVES, N. P. S. Produtividade da cultura da abóbora em diferentes densidades de plantio no Vale do São Francisco. Horticultura Brasileira, v. 31, n. 3, p. 504-508, 2013.

RODO, A. B.; TILLMANN, M. A. A.; VILLELA, F. A. Testes de vigor na avaliação da qualidade fisiológica de sementes de tomate. Revista Brasileira de Sementes, v. 20, p. 23-28, 1998.

SANTOS, V. J. et al. Qualidade fisiológica de sementes de cenoura classificadas por tamanho. Ciência Rural, v. 40, n. 9, p. 1903-1908, 2010.

TILLMANN, M. A. A.; MENEZES, N. L. Análise de Sementes. In: PESKE, S. T.; VILLELA, F. A.; MENEGHELlO, G. E. (Ed.). Sementes: fundamentos científicos e tecnológicos. Pelotas: Editora e Gráfica Universitária, 2012. p. 62-272.

TORRES, S. B.; MARCOS FILHO, J. Physiological potential evaluation in melon seeds (Cucumis melo L.). Seed Science and Technology, v. 33, p. 341-350, 2005.

VAZQUEZ, G. H. et al. Influência do tamanho e da forma da semente de milho sobre o desenvolvimento da planta e a produtividade de grãos. Bioscience Journal, v. 28, n. 1, p. 16-24, 2012.

Recebido: 23 nov. 2014 Aprovado: 17 nov. 2015 